\section{Long-term results of Ahmed glaucoma valve and Molteno implant in neovascular glaucoma}

IS Yalvac, U Eksioglu, B Satana and S Duman

\begin{abstract}
Aims To evaluate the surgical success results of Ahmed glaucoma valve (AGV) and Molteno single-plate implant (MSPI) in cases of neovascular glaucoma (NVG).

Methods Between May 1997 and May 2002, 38 of 38 NVG patients that underwent implantation of AGV and 27 eyes of 27 NVG patients that underwent MSPI (a total 65 eyes of 65 patients) included to the study. Results The cumulative probabilities of success were $63.2 \%$ at 1 year, $56.2 \%$ at 2 years, $43.2 \%$ at 3 years, $37.8 \%$ at 4 years, and $25.2 \%$ at 5 years in AGV group whereas the cumulative probabilities of success were $37.0 \%$ at 1 year,

surgery. Several therapies have been used including trabeculectomy with antimetabolites, ${ }^{1}$ cyclocryotherapy, ${ }^{2} a b$ interno and externo laser cyclophotocoagulation $^{3}$ and each technique has demonstrated generally poor success rates. Artificial aqueous drainage devices have been advocated for primary surgical treatment of NVG but general success rates varied in different studies. ${ }^{4-8}$

In this retrospective study, we evaluated 5-year efficacy and safety of Molteno singleplate implant (MSPI) without pressure ridge and Ahmed glaucoma valve (AGV) in eyes with NVG and examined the factors that influence the outcome.
\end{abstract} $29.6 \%$ at 2 years, $29.6 \%$ at 3 years, $29.6 \%$ at 4 years, and $29.6 \%$ at 5 years in MSPI group $(P=0.141)$. Preoperative visual acuity $<2 / 200$ $(P=0.003)$, diagnosis of diabetes mellitius $(P=0.050)$, and preoperative IOP $\geq 35 \mathrm{mmHg}$ $(P=0.038)$ were found to be poor prognostic factors for surgical success.

Conclusions Both AGV and single plate MSPI were successful for early and intermediate-term of IOP control but in long term both implants were failed to achieve control of IOP in patients with NVG. Eye (2007) 21, 65-70. doi:10.1038/sj.eye.6702125; published online 7 October 2005

Keywords: neovascular glaucoma; Ahmed glaucoma valve; Molteno tube implantation; seton

\section{Introduction}

The management of neovascular glaucoma (NVG), represents a challenge and usually responds poorly to conventional glaucoma
Patients and methods

Patients

After approval by the local Ethic Committe of Ankara Research and Education Hospital, the charts of all patients with NVG and operated with tube implantation from the period May 1997-May 2002 reviewed retrospectively. Total 65 consecutive patients of 65 eyes and 38 eyes of 38 patients treated with an AGV Model S-2 (New World Medical Inc., Rancho Cucamonga, CA, USA) and 27 eyes of 27 patients treated with a MSPI without the pressure-ridge are included the study (Molteno Ophthalmic Ltd, Dunedin, New Zealand). The demographic features of the patients are listed in Table 1.

A total of $37(94.7 \%)$ patients in AGV group and 25 patients $(92.6 \%)$ in MSPI group had undergone retinal photocoagulation or postequatorial cryoablation before surgical intervention. Only the first eye of patients who had bilateral surgery was considered in the analysis of surgical outcomes.
Department of

Ophthalmology, Ankara Education and Research Hospital, Ankara, Turkey

Correspondence: IS Yalvac, Cinnah Caddesi 26/4, Cankaya 06680, Ankara, Turkey Tel: + 9031242815 16; Fax: + 903124281509 E-mail: iyalvac@ hotmail.com

Received: 14 April 2005 Accepted in revised form: 14 August 2005 Published online: 7 October 2005

The authors have no proprietary interest in any device or technique described in this study

Partly presented at the Turkish Satellite Meeting, 5th International Glaucoma Symposium (IGS),

Cape Town, South Africa; March 2005 
Table 1 Demographic data

\begin{tabular}{|c|c|c|c|}
\hline & Ahmed glaucoma valve $N: 38$ & Molteno tube implant N:27 & $\mathrm{P}$ \\
\hline $\begin{array}{l}\left.\text { Follow-up (mos) (mean } \pm S D^{*}\right) \\
\quad \text { Range (mos) }\end{array}$ & $\begin{array}{c}37.0 \pm 18.4 \\
(6-60)\end{array}$ & $\begin{array}{r}41.9 \pm 17.1 \\
(6-60)\end{array}$ & $P^{* *}=0.289$ \\
\hline $\begin{array}{l}\text { Age (years) (mean } \pm S D) \\
\text { Range (years) }\end{array}$ & $\begin{array}{r}57.7 \pm 10.9 \\
(24-74)\end{array}$ & $\begin{aligned} 58.3 \pm 15.4 \\
(14-77)\end{aligned}$ & $P^{* * *}=0.368$ \\
\hline \multicolumn{4}{|l|}{ Sex } \\
\hline $\begin{array}{l}\text { Female } \\
\text { Male }\end{array}$ & $\begin{array}{l}17(55.3 \%) \\
21(44.7 \%)\end{array}$ & $\begin{array}{r}18(66.7 \%) \\
9(33.3 \%)\end{array}$ & $P^{* *}=0.355$ \\
\hline \multicolumn{4}{|l|}{ Cause of neovascularisation } \\
\hline $\begin{array}{l}\text { Diabetic retinopathy } \\
\text { Central retinal vein occlusion }\end{array}$ & $\begin{array}{l}19(50 \%) \\
17(44.7 \%)\end{array}$ & $\begin{array}{l}15(55.6 \%) \\
10(37 \%)\end{array}$ & \\
\hline Ocular ischaemic syndrome & $2(5.2 \%)$ & $1(3.7 \%)$ & $P^{* *}=\mathrm{NA}$ \\
\hline Coats' disease & - & $1(3.7 \%)$ & \\
\hline
\end{tabular}

*SD.

**Student's $t$ test.

***Mann-Whitney $U$ test.

All tube implantation procedures were performed by three experienced glaucoma surgeons (ISY, UE, BS). We randomly selected the type of the implant for our patients.

\section{Surgical technique}

A fornix-based conjunctival flap was created between two adjacent recti muscles and extended $90^{\circ}$. Before placement of the tube implant body to the sclera, tube was irrigated with saline solution to open the valve mechanism. The implant's polypropylene body was sutured to sclera with 6.0 polyester suture. In MSPI group, tube was tied off with an absorbable 6.0 vicryl suture, $3 \mathrm{~mm}$ from plate, to prevent postoperative hypotony. The tube then trimmed and the anterior chamber was entered from $1 \mathrm{~mm}$ posterior to corneoscleral limbus with 23-gauge needle. A human donor pericardium was placed over the tube and sutured to the sclera with 10.0 nylon suture. The conjunctiva was sutured to the limbus.

\section{Postoperative follow-up}

The following information was documented for each patient preoperatively; age, gender, etiology of NVG, visual acuity, and intraocular pressure (IOP) before tube implant surgery. Postoperative visual acuity and IOP was recorded at each visit after tube implant surgery. The number of postoperative glaucoma medications, optic disc appearance, early (0-3 months) and late postoperative complications were also recorded. 'Hypertensive phase' has been defined as IOP greater than $21 \mathrm{mmHg}$ in the first 6 postoperative months.

\section{Criteria for success and failure}

Surgical success was defined as IOP $<22 \mathrm{mmHg}$ and $>5 \mathrm{mmHg}$ without additional glaucoma surgery and without loss of light perception. Postoperative use of antiglaucoma medications was not accepted as a criterion of success or failure. The definition of hypotony in this study was IOP of $5 \mathrm{mmHg}$ or less in two consecutive visits. Also, we compared the cumulative probablity of success rates in the patients according to age, gender, preoperative visual acuity, IOP, and aetiology of NVG.

\section{Statistical analysis}

WinSTAT for Microsoft Excel Version 2001.1 program was used for statistical analysis. The paired $t$-tests and Mann-Whitney $U$ tests were used to assess differences in continiously scaled variables before and after surgery. Mantel-Haenszel $\chi^{2}$ test was used for comparision of the qualitative data between the two groups. The cumulative probability of success was analysed by Kaplan-Meier life-table analysis and intercurve analysis was performed using the log-rank test. A statistically significant difference was defined as a $P$-value $<0.05$.

\section{Results}

\section{Patient characteristics}

A total of 38 patients in AGV group and 27 in MSPI group and a total of 65 patients were included in the study (Table 1). 


\section{Intraocular pressure}

As shown in Table 2 and Figure 1 the mean preoperative IOP was $39.5 \pm 4.5 \mathrm{mmHg}(31-56 \mathrm{mmHg})$ in AGV group, $39.3 \pm 3.9 \mathrm{mmHg}(30-45 \mathrm{mmHg})$ in MSPI group $(P=0.882)$.

The AGV group showed a greater decline in IOP at each visit postoperatively and it was statistically significant at $3(P=0.009)$ and 6 months $(P=0.040)$ postoperatively. The percentage of reduction in IOP was $52.6 \%$ in AGV group and $57.7 \%$ in MSPI group at last visit.

Hypertensive phase was present by $7 / 38$ (18.4\%) patients in AGV group whereas 8/27 (29.6\%) patients in MSPI group, respectively. This period was controlled with antiglaucoma medications in all patients in both groups.

\section{Surgical success}

The Kaplan-Meier life-table analysis of the total 65 patients were $52.3 \%$ at 1 year, $44.8 \%$ at 2 years, $37.8 \%$ at 3 years, $34.6 \%$ at 4 years, $26 \%$ at 5 years in all implant

Table 2 Mean IOP Profile before and after placement of Ahmed glaucoma valve and Molteno single plate implant in patients with neovascular glaucoma

\begin{tabular}{|c|c|c|c|}
\hline & $\begin{array}{c}\text { Ahmed glaucoma } \\
\text { valve IOP* } \pm S D^{* *} \\
\quad N: 38(m m H g)\end{array}$ & $\begin{array}{c}\text { Molteno tube } \\
\text { implant } I O P \pm S D \\
N: 27(m m H g)\end{array}$ & $\mathrm{P}^{* * *}$ \\
\hline Preoperative & $\begin{array}{c}39.5 \pm 4.5 \\
(31-56)\end{array}$ & $\begin{array}{c}39.3 \pm 3.9 \\
(30-45)\end{array}$ & 0.882 \\
\hline \multicolumn{4}{|l|}{ Postoperative } \\
\hline 3 months & $\begin{array}{c}15.6 \pm 8.0 \\
(4-35)\end{array}$ & $\begin{array}{c}21.3 \pm 9.6 \\
(3-38)\end{array}$ & $0.009^{\mathrm{a}}$ \\
\hline 6 months & $\begin{array}{c}17.8 \pm 7.2 \\
(5-34)\end{array}$ & $\begin{array}{c}20.9 \pm 6.8 \\
(6-34)\end{array}$ & $0.040^{\mathrm{a}}$ \\
\hline 1 year & $\begin{array}{c}19.7 \pm 6.7 \\
(4-36)\end{array}$ & $\begin{array}{c}20.8 \pm 7.7 \\
(4-36)\end{array}$ & 0.552 \\
\hline 2 years & $\begin{array}{c}21.5 \pm 6.9 \\
(6-34)\end{array}$ & $\begin{array}{c}21.0 \pm 6.5 \\
(10-30)\end{array}$ & 0.851 \\
\hline 3 years & $\begin{array}{c}21.6 \pm 5.9 \\
(6-32)\end{array}$ & $\begin{array}{c}22.2 \pm 5.4 \\
(12-29)\end{array}$ & 0.758 \\
\hline 4 years & $\begin{array}{c}21.5 \pm 5.6 \\
(6-28)\end{array}$ & $\begin{array}{c}21.1 \pm 4.3 \\
(14-27)\end{array}$ & 0.596 \\
\hline 5 years & $\begin{array}{c}20.8 \pm 8.6 \\
(2-35)\end{array}$ & $\begin{array}{c}22.7 \pm 4.2 \\
(13-27)\end{array}$ & 0.447 \\
\hline
\end{tabular}

adenotes statistical significance.

*Intraocular pressure

$* * \mathrm{SD}$.

***Mann-Whitney $U$ test. groups. Mean survival time of the all patients by KaplanMeier survival analysis was 29 months (Figure 2).

The overall success rates of the AGV were $63.2 \%$ at 1 year, $56.1 \%$ at 2 years, $43.2 \%$ at 3 years, $37.8 \%$ at 4 years, and $25.2 \%$ at 5 years. Mean survival time of the AGV patients by Kaplan-Meier survival analysis was 34 months (Figure 3).

The success rates of MSPI were 37, 29.6, 29.6, 29.6, $29.6 \%$, respectively. Mean survival time of the MSPI patients by Kaplan-Meier survival analysis was 22 months (Figure 3).

Although the success rates always higher in AGV group in all periods of time, the log-rank test indicated no significant difference between the two groups $(P=0.141)$.

\section{Success and age}

Patients older than 50 years of age were more likely to have a successful results (Age $<50$ years $21.43 \%$ vs Age $\geqslant 50$ years $41.18 \%$ ) in all groups but it was not statistically significant $(P=0.925)$.

We also compared surgical success rates between AGV and MSPI groups in 50 years older and younger NVG patients but it was not statistically significant $(P=0.144)$.

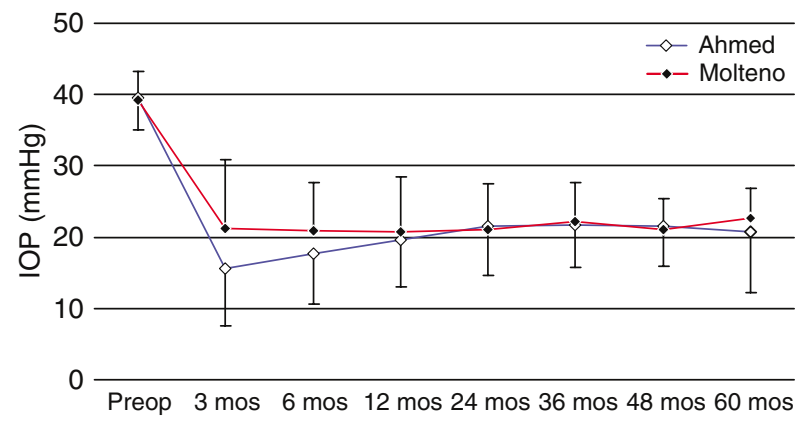

Figure 1 Mean Intraocular Pressure changes from baseline to 60 months follow-up between the groups.

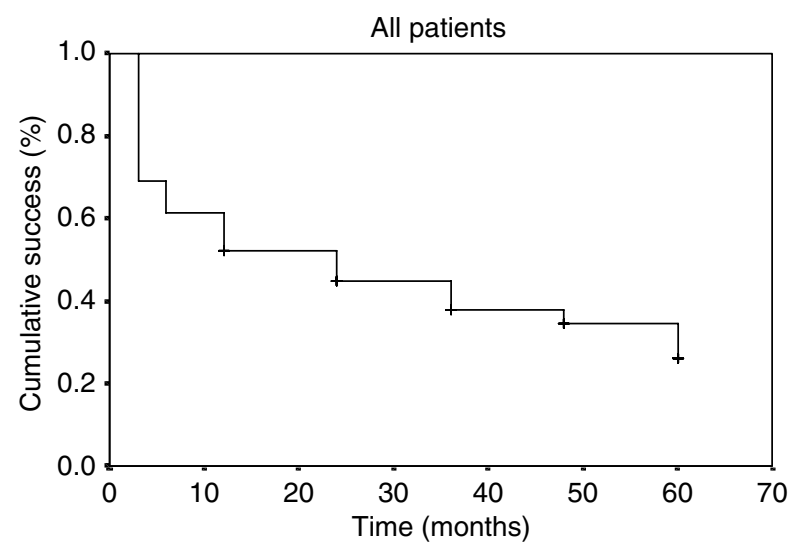

Figure 2 Cumulative probability of success of the all implant patients over a 5-year period. 


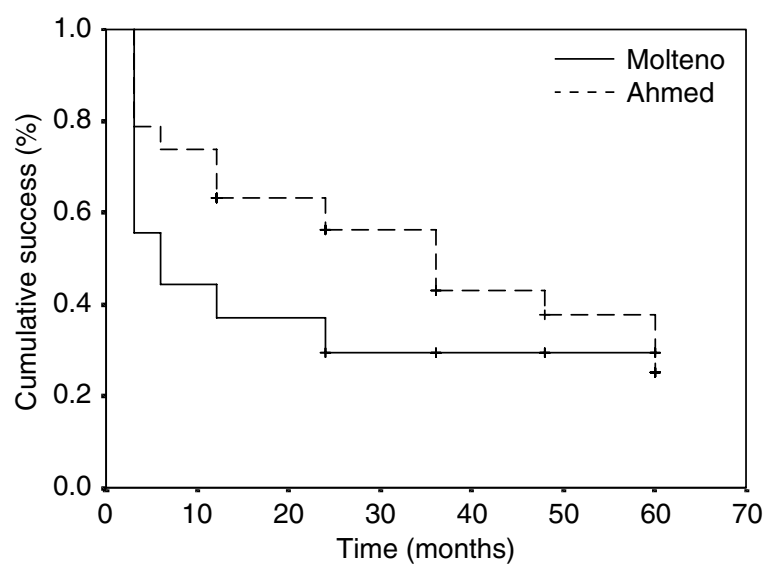

Figure 3 Cumulative probability of success of the Ahmed Glaucoma Valve group and Molteno Single Plate Implant group over a 5-year period in NVG patients. ( $P=0.141$, Log-rank test).

\section{Success and gender}

The success rate of male gender was $41.03 \%$ and female gender was $30.77 \%$ in all groups and it was not statistically significant $(P=0.267)$. There was also no statistically significant difference between the two groups in terms of gender $(P=0.074)$.

\section{Success and preoperative visual acuity}

We compared all patients according to their preoperative visual acuities better than $2 / 200$ or worse. The patients with preoperative visual acuity better than $2 / 200$ achieved statistically significant surgical success than visual acuity $<2 / 200(P=0.003)$.

\section{Success and diagnosis}

Patients with CRVO had a better surgical outcome than $\mathrm{DM}$, and this was statistically significant $(P=0.050, \log$ rank test). Success rate of CRVO was $48.15 \% 50$ vs $23.53 \%$ in DM group in all patients. According to implant type, CRVO patients was more successful than DM patients in both groups (48.15 and $52.94 \%$ in AGV group vs 23.53 and $26.32 \%$ in MSPI group) $(P=0.083)$.

\section{Success and preoperative IOP}

The success rate of the patients with preoperative IOP $\geq 35 \mathrm{mmHg}$ in all group was not statistically significant ( $P=0.106$, log-rank test) but AGV patients were more successful than MSPI patients according to preoperative IOP $\geq 35 \mathrm{mmHg}(P=0.038)$.

\section{Glaucoma medications}

The mean number of glaucoma medications was reduced from $3.4 \pm 0.5$ in the preoperative period to $1.7 \pm 1.6$ in last postoperative visit in AGV group $(P=0.000)$ and from
$3.4 \pm 0.5$ to $1.8 \pm 1.2(P=0.000)$ respectively, in MSPI group.

\section{Visual acuity}

All patients had a preoperative visual acuity of at least light perception. A decrease in the visual acuity of more than two Snellen lines of the best corrected visual acuity on at least two postoperative visits was defined as failure. Visual acuity was improved in five patients (13.2\%) in AGV group and three patients (11.1\%) in MSPI group. Visual failure was 9/38 (23.6\%) in AGV group and $9 / 27(33.3 \%)$ in MSPI group. Only three $(7.8 \%)$ of these patients in AGV group and four (14.8\%) of these patients in MSPI group demonstrated inadequate control of IOP (ie, $>21 \mathrm{mmHg}$ ) at most recent follow-up. In most cases, decreased visual acuity was attributed to progression of the underlying retinal disease. Five (13\%) patients in AGV group and six (22.2\%) patients in MSPI group lost light perception during the follow-up period pre- and postoperative visual acuity changes were not statistically significant between the groups $(P=0.485)$ (Table 3).

\section{Complications}

The most common complication in the early postoperative period ( $0-3$ months) was hyphema in both groups (Table 4). All the hyphemas were reabsorbed without any surgical intervention. Tube occlusion occurred in three (7.9\%) eyes in AGV group and four

Table 3 Postoperative change in visual acuity

\begin{tabular}{lccc}
\hline Visual acuity & $\begin{array}{c}\text { Ahmed glaucoma } \\
\text { valve N:38(\%) }\end{array}$ & $\begin{array}{c}\text { Molteno tube } \\
\text { implant N:27 (\%) }\end{array}$ & $\mathrm{P}^{*}$ \\
\hline Same & $24(63.2)$ & $15(60)$ & 0.413 \\
Decreased & $9(23.6)$ & $9(33.3)$ & 0.126 \\
Improved & $5(13.2)$ & $3(11.1)$ & 0.457 \\
\hline
\end{tabular}

*Mann-Whitney $U$ test.

Table 4 Early (0-3 months) postoperative complications

\begin{tabular}{lcc}
\hline & $\begin{array}{c}\text { Ahmed glaucoma } \\
\text { valve number } \\
(\%) N: 38\end{array}$ & $\begin{array}{c}\text { Molteno tube } \\
\text { implant number } \\
(\%) ~ N: 27\end{array}$ \\
\hline Hyphema & $7(18.4)$ & $7(25.9)$ \\
Tube occlusion & $3(7.9)$ & $4(14)$ \\
Choroidal effusion & $2(5.3)$ & $5(18.5)$ \\
Shallow AC & $2(5.3)$ & $4(14.8)$ \\
Hypotonia & $2(5.3)$ & $2(7.4)$ \\
Tube-cornea touch & $1(2.6)$ & $1(3.7)$ \\
Suprachoroidal haemorrhage & - & $1(3.7)$ \\
\hline \multicolumn{3}{c}{}
\end{tabular}


Table 5 Late ( $>3$ months) postoperative complications

\begin{tabular}{lcc}
\hline & $\begin{array}{c}\text { Ahmed glaucoma } \\
\text { valve number } \\
(\%)\end{array}: 38$ & $\begin{array}{c}\text { Molteno tube } \\
\text { implantation number } \\
\text { (\%) } N: 27\end{array}$ \\
\hline Phthisis Bulbi & $3(7.9)$ & $4(14.8)$ \\
Encapsulated plate & $3(7.9)$ & $3(11.1)$ \\
Tube/plate exposure & $2(5.3)$ & $3(11.1)$ \\
Corneal decompansation & $2(5.3)$ & $3(11.1)$ \\
Diplopia & - & $1(3.7)$ \\
\hline
\end{tabular}

(14\%) eyes in MSPI group and treated with tube irrigation (five eyes 18.5\%) and argon laser photocoagulation to iris around the tube (two eyes 5.3\%). Choroidal effusion was developed in two (5.3\%) eyes in AGV group and five (18.5\%) eyes in MSPI group. All the eyes had peripheral serous choroidal detachments and none of these was drained. One (3.7\%) patient in MSPI group had a suprachoroidal haemorrhage and it was drained surgically. Hypotonia occurred in two eyes (5.3 and $7.4 \%$, respectively) in both groups. Two eyes $(5.3 \%)$ in AGV group and four eyes (14.8\%) in MSPI group developed shallow anterior chambers. The anterior chamber of the two eyes in MSPI group was reformed during the first postoperative week because of lenscorneal touch.

The main late postoperative complication of the both groups was phthisis bulbi in three eyes $(7.9 \%)$ in AGV group and four eyes (14.8\%) in MSPI group. (Table 5) Phthisis bulbi was secondary to progression of the proliferative retinopathy in all cases. Three eyes (7.9\%) with encapsulated bleb, two underwent needling + Mitomycin-C injection in AGV group and three eyes $(11.1 \%)$ of all underwent same procedure in MSPI group.

\section{Discussion}

The aim of surgical treatment in NVG is reducing IOP with preserving visual functions and reducing pain. ${ }^{6-8}$ In this study, MSPI and AGV implants are achieved a marked IOP lowering effect (Figure 1). These reductions were statistically significantly lower in AGV group in 3 and 6 months postoperatively than MSPI group $(P<0.005)$. A period of transient elevation of IOP, termed the 'hypertensive phase' has been described after glaucoma drainage implant surgery. 9,10 This phase was present by 15.8 and $18.4 \%$ patients in AGV group whereas 33.3 and $29.6 \%$ patients in 3 and 6 months in MSPI group, respectively. The lower level of hypertensive phase may be due to to the intermediatesized plate of the AGV implant than MSPI in our study. Ayyala et $a l^{10}$ noted a $83.5 \%$ hypertensive phase of AGV vs $43.5 \%$ of double plate Molteno implant in patients with advanced glaucoma. The low rate of this phase could be related to medications that we used in this period or ciliary ischaemia in NVG.

Difficulty often exists in comparision of intermediateterm and long-term follow-up studies because of lack of uniform success criterias and uniform patient demographics. Mermoud et $a l^{6}$ have studied the longterm results of single-plate Molteno implants in NVG. Success rates at the 1- to 5-year intervals were $62.1-10.3 \%$, respectively in this study. These results up to the 5-year postoperative period are higher than MSPI and lower than AGV and all groups (MSPI + AGV) in our study. We noted a substantial decrease in success rates starting at 2 years after surgery (Figures 2 and 3). The surgical success rate was influenced significantly by preoperative visual acuity $<2 / 200(P=0.0003)$,

IOP $\geq 35 \mathrm{mmHg}(P=0.038)$ and the diagnosis of diabetes mellitus $(P=0.050)$ in all groups. These above findings contrast with those reported by Mermoud et al, ${ }^{6}$ in which preoperative age less than 55, and diagnosis of central vein occlusion were more predictive of poor surgical outcome. Similarly, Sidoti et al, ${ }^{7}$ found that poorer preoperative visual acuity was significant predictors of surgical failure with the Baerveldt glaucoma implant in NVG. They also $^{7}$ reported that implant size had no significant effect on surgical outcome. The need for a larger surface area for aqueous drainage in NVG may be minimized because of subnormal aqueous production secondary to ciliary body ischaemia. In our study, we did not find statistically significant difference in term of success in both implants in all time periods. Britt et $a l^{11}$ found that $350-\mathrm{mm}^{2}$ Baerveldt implant is more successful than the $500-\mathrm{mm}^{2}$ implant for IOP control in refractory glaucoma in long-term follow-up. Also, Broadway et al ${ }^{12}$ found no statistical difference between single and double plate Molteno implant in terms of clinical success in refractory glaucoma cases over a 10-year follow-up. The high rate of surgical failure is mainly due to the loss of vision secondary to progression of underlying disease in neovascular patients. ${ }^{6,7}$ In our series five (13\%) patients in AGV group, and six (22.2\%) patients in MSPI group lost light perception during the follow-up period. Loss of light perception was reported between 11 and $48 \%$ of eyes after tube implantation in NVG. ${ }^{4-7}$ Second cause of failure was phitisis bulbi in three eyes $(7.9 \%)$ in AGV group and four eyes (14.8\%) in MSPI group in our study. Phthisis bulbi was secondary to progression of the proliferative retinopathy in all cases. Recently, Delgado et $a l^{13}$ reported loss of light perception $17.6 \%$ of all eyes treated with noncontact transscleral Nd:YAG laser cyclophotocuagulation in NVG.

Hyphema was the most common complication in early postoperative period. It was reported between 8 and $20 \%$ 
with tube implantation in NVG. ${ }^{6,7}$ All the hyphemas resorbed without surgical intervention in both groups. Hypotony was seen in two patients in each group $(5.3 \%$ and $7.4 \%$, respectively) (Table 4 ). Postoperative hypotony was found between 8 and $13 \%$ with AGV. ${ }^{14,15}$ Krishna et $a l^{16}$ found $5 \%$ hypotony maculopathy and flat anterior chamber $14 \%$ after implantation of $350-\mathrm{mm}^{2}$ Baerveldt implant. Hypotony and related complications were quite similar in both implant groups in our study. We think that since performing tube ligation techniques in nonvalved implants, hypotony has not become a dreadful complication at early postoperative period. Corneal decompansation was seen in $5.3 \%$ patients in AGV and $11.1 \%$ patients in MSPI group (Table 5). Corneal decompansation following placement of drainage implants has been reported up to $27 \%$ of eyes. ${ }^{17-21}$ In our patients corneal decompansation was not a major contributing factor for loss of vision and tube failure.

In conclusion, both AGV and MSPI are effective for lowering IOP in NVG patients. However, in long-term follow-up, both implants were poor for maintaining clinical success survival because underlying retinal disease progression. Preoperative poor visual acuity, diagnosis of diabetes mellitus and preoperative high IOP levels were main bad prognostic factors for tube implantation in NVG.

\section{Acknowledgements}

We thank to Mr Oktay Özdemir and OMEGA Group for statistical consultations.

\section{References}

1 Tsai JC, Feuer WJ, Parrish II RK, Grajewski AL. 5-Fluorouracil filtering surgery and neovascular glaucoma. Long-term follow-up of the original pilot study. Ophthalmology 1995; 102: 887-893.

2 Krupin T, Mitchell KB, Becker B. Cyclocryotheraphy in neovascular glaucoma. Am J Ophthalmol 1978; 86: 24-26.

3 Uram M. Ophthalmic laser microendoscope ciliary process ablation in management of neovascular glaucoma. Ophthalmology 1992; 99: 1832-1838.

4 Eid TE, Katz LJ, Spaeth GL, Augsburger JJ. Tube-shunt surgery $v s$ neodymium:YAG cyclophatocoaculation in the management of neovascular glaucoma. Ophthalmology 1997; 104: 1692-1700.

5 Krupin T, Mandell A, Ritch R, Asseff C, Podos SM, Becker B. Filtering valve implant surgery for eyes with neovascular glaucoma. Am J Ophthalmol 1980; 89: 338-343.

6 Mermoud A, Salmon JF, Alexander P. Molteno tube implantation for neovascular glaucoma. Long-term results and factors influencing the outcome. Ophthalmology 1993; 100: 897-902.

7 Sidoti PA, Dunphy TR, Baerveldt G, LaBreeet L, Minckler DS, Lee PP et al. Experience with the Baerveldt glaucoma implant in treating neovascular glaucoma. Ophthalmology 1995; 102: 1107-1118.

8 Sivak-Callcott JA, O'Day DM, Gass JDM, Tsai JC. Evidencebased recommendations for the diagnosis and treatment of neovascular glaucoma. Ophthalmology 2001; 108: 1767-1776.

9 Ayyala RS, Zurakowski D, Smith JA, Monshizadeh R, Netland PA, Richards DW et al. A clinical study of the Ahmed glaucoma valve implant in advanced glaucoma. Ophthalmology 1998; 105: 1968-1976.

10 Ayyala RS, Zurakowski D, Monshizadeh R, Hong CH, Richards DW, Layden WE et al. Comparision of Doubleplate Molteno and Ahmed glaucoma valve in patients with advanced uncontrolled glaucoma. Ophthalmic Surg Lasers 2002; 33: 94-101.

11 Britt MT, LaBree LD, Lloyd MA, Minckler DS, Heuer DK, Baerveldt $\mathrm{G}$ et al. Randomized clinical trial of the $350-\mathrm{mm}^{2}$ vs the $500-\mathrm{mm}^{2}$ Baerveldt implant: Longer term results. Is bigger better? Ophthalmology 1999; 106: 2312-2318.

12 Broadway DC, Iester M, Schulzer M, Douglas GR. Survival analysis for success of Molteno tube implants. $\mathrm{Br} \mathrm{J}$ Ophthalmol 2001; 85: 689-695.

13 Delgado MF, Dickens CJ, Iwach AG, Novack GD, Nychka DS, Wong PC et al. Long-term results of Neodymium:Yttrium-Aluminum-Garnet cyclophotocoagulation in neovascular glaucoma. Ophthalmology 2003; 110: 895-899.

14 Huang MC, Netland PA, Coleman AL, Siegner SW, Moster MR, Hill RA. Intermediate-term clinical experience with the Ahmed Glaucoma valve implant. Am J Ophthalmol 1999; 127: 27-33.

15 Coleman AL, Hill R, Wilson R, Choplin N, Kotas-Neumann $\mathrm{R}$, Bacharach $\mathrm{J}$ et al. Initial clinical experience with Ahmed glaucoma valve implant. Am J Ophthalmol 1995; 120: 23-31.

16 Krishna R, Godfrey DG, Budenz DL, Escalona-Camaano E, Gedde SJ, Greenfield DS et al. Intermediate-term outcomes of 350- $\mathrm{mm}^{2}$ Baerveldt Glaucoma Implants. Ophthalmology 2001; 108: 621-626.

17 Taglia DP, Perkins TW, Gangnon R, Heatley GA, Kaufman P. Comparision of the Ahmed glaucoma valve, the Krupin eye valve with disk and the Double-plate Molteno Implant. J Glaucoma 2002; 11: 347353.

18 Krupin eye valve with disk for filtration surgery. The Krupin Eye Valve Filtering Surgery Study Group. Ophthalmology 1994; 101: 651-658.

19 Lloyd MA, Sedlak T, Heuer DK, Minckler DS, Baerveldt G, Lee MB et al. Clinical experience with the single-plate Molteno implant in complicated glaucomas: update of a pilot study. Ophthalmology 1992; 99: 679-687.

20 Topouzis F, Coleman AL, Choplin N, Bethlem M, Hill R, $\mathrm{Yu} \mathrm{F}$ et al. Follow-up of the original cohort with the Ahmed glaucoma valve implant. Am J Ophthalmol 1999; 128: 198-204.

21 Mills RP, Reynolds A, Emond MJ, Barlow WE, Leen MM. Long-term survival of Molteno glaucoma drainage devices. Ophthalmology 1996; 103: 299-305. 